\title{
Biomimetic norfloxacin sensors made of molecularly-imprinted materials for potentiometric transduction
}

\author{
Felismina T. C. Moreira • Victor A. P. Freitas • \\ Maria G. F. Sales
}

\begin{abstract}
A biomimetic sensor for norfloxacin is presented that is based on host-guest interactions and potentiometric transduction. The artificial host was imprinted into polymers made from methacrylic acid and/or 2-vinyl pyridine. The resulting particles were entrapped in a plasticized poly(vinyl chloride) (PVC) matrix. The sensors exhibit near-Nernstian response in steady state evaluations, and detection limits range from 0.40 to $1.0 \mu \mathrm{gmL}^{-1}$, respectively, and are independent of $\mathrm{pH}$ values at between 2 and 6 , and 8 and 11, respectively. Good selectivity was observed over several potential interferents. In flowing media, the sensors exhibit fast response, a sensitivity of $68.2 \mathrm{mV}$ per decade, a linear range from $79 \mu \mathrm{M}$ to $2.5 \mathrm{mM}$, a detection limit of $20 \mu \mathrm{gmL}^{-1}$, and a stable baseline. The sensors were successfully applied to field monitoring of norfloxacin in fish samples, biological samples, and pharmaceutical products.
\end{abstract}

Keywords Norfloxacin · Molecularly-imprinted sensors . Potentiometry · FIA · Fish

\section{Introduction}

Industrial aquaculture is a rapidly growing industry in many developed and developing countries [1]. A significant growth at food fish production has been observed over the past decade, due to the prevention or elimination of fish diseases. The introduction of veterinary medicines such as antimicrobials at the food production area has been the main responsible for this scenario. However, the wide use of antibiotics in aquaculture led to environmental and food spread of antimicrobials, and may result in the emergence of antibiotic-resistant bacteria in aquaculture environments $[1,2]$. For food safety purposes, fish samples must be subject of rigorous and frequent controls that ensure that residues of antimicrobials are below the maximum legal levels [3].

Norfloxacin (NOR) (1-ethyl-6-fluoro-1,4-dihydro-4-oxo-7(1-piperazinyl)quinoline-3-carboxylic acid,) is a fluoroquinolone antibacterial agent which exhibits high antimicrobial activity in vitro against a wide variety of gram-negative and gram-positive bacteria, including gentamicin-resistant Pseudomonas aeruginosa and methicillin-resistant Staphylococcus aureus species [4]. Norfloxacin has a remarkably broad spectrum of activity and excellent pharmacokinetics allowing for once daily dosing [5]. NOR is one of the several antimicrobials administered to fish in aquaculture environment. Its residues are potentially persistent [6] and may be found in fish [7], for which fish meat should be subject to routine and rigorous control by means of suitable analytical techniques [8].

Analytical procedures suggested in literature for NOR regard microbiological methods $[9,10]$ or liquidchromatographic techniques with mass-spectrometry [11, 12], fluorescence $[13,14]$ and/or with combination of Ultraviolet, Diode-Array or mass-spectrometry detection $[10,15,16]$. The former is unsuitable for routine control 
procedures, as each trial may take several days; laboratories require also proper facilities to handle biological compounds safely. Chromatographic techniques are accurate, precise and robust, but they are not as expeditious as required for routine control purposes. They may also contribute to the emission of effluents of high toxicity. The same comments may apply to the electrophoretic-based procedures reported in literature [16]. Other methods are based on immunoassays [17]; although they provide specific responses, the overall procedure is long and too expensive for routine analytical measurements.

Alternative and advantageous methods should rely on expeditious and efficient procedures providing highly specific and sensitive measurements. Ion-selective electrodes (ISEs) offer high precision and rapidity, low cost of analysis, enhanced selectivity and sensitivity over a wide range of concentrations [18]. The most vital component of these sensing devices in terms of selectivity and sensitivity is the ionophore or the ion carrier, as its binding to the target ion is the molecular-level phenomenon sensed by an ISE. Ion exchangers and neutral macrocyclic compounds have been the "vital components" employed over the past decades for polymeric membrane potentiometric transduction, but the design of sensing materials that are complementary to the size and charge of a particular ion can lead to very selective interactions, thus enhancing the selectivity of the sensing unit. Molecularly-imprinted polymers (MIPs) can be easily tailored with selectivity for a guest molecule [19]. Their stability at extremes of $\mathrm{pH}$ and temperature, high mechanical strength, low cost, and reusability have led to the development of various MIP applications, including chromatography [20], artificial antibodies [21], chemical sensors [22], and solid-phase extraction [23].

Although MIPs may also be used as sensing materials of ISEs [24], only few works report their use as potentiometric sensors [25-27]. The association of MIP to ISEs has the advantage of avoiding the need of template extraction from the host-tailored particle. This extraction may leave vacant recognition sites, ready for binding, which is a typical source of uncertainty at the determination or a sensitivity-limiting factor. In addition, there is no size restriction on the template compound because it does not have to diffuse through the membrane.

The present work describes the development of NOR MIP-based ISEs. The sensor is synthesized with methacrylic acid (MAA) and 2-vinyl pyridine (VP) functional monomers, cross-linked by ethylene glycol dimethacrylic acid (EGDMA) within the template molecule. The sensing materials are dispersed in a PVC matrix plasticized with $o$ nitrophenyl octyl ether (oNPOE). The sensors are evaluated in steady-state and flowing media, and applied to the analysis of contaminated fish samples, biological fluids and pharmaceutical products.

\section{Experimental}

Apparatus and chemicals

All potential measurements were made by a Crison $\mu \mathrm{pH}$ 2002 decimilivoltammeter $( \pm 0.1 \mathrm{mV}$ sensitivity), at room temperature, and under constant stirring, by means of a Crison, micro ST 2038. The output signal in steady state evaluations was transferred to a commutation unit and reconnected to one of six ways out, enabling the simultaneous reading of six ISEs. The assembly of the potentiometric cell was as follows: conductive graphite | NOR selective membrane | buffered sample solution (HEPES, $\left.1.0 \times 10^{-2} \mathrm{molL}^{-1}, \mathrm{pH} 5.5\right) \|$ electrolyte solution, $\mathrm{KCl} \mid$ $\mathrm{AgCl}(\mathrm{s}) \mid \mathrm{Ag}$. The reference electrode was an Orion $\mathrm{Ag} /$ $\mathrm{AgCl}$ double-junction (Orion 90-02-00). The selective electrode was prepared in conventional or tubular configurations [24] for batch and flow mode evaluations, respectively. Both devices had no internal reference solution and epoxy-graphite was used as solid contact.

The Flow Injection Analysis (FIA) assembly had a Gilson Minipuls two peristaltic pump, fitted with PVC tubing $(0.80,1.60 \mathrm{and} /$ or $2.00 \mathrm{~mm}$ i.d.), and a four-way Rheodyne 5020 injection valve holding a loop of variable volume. The several components were joined by PTFE tubing (Omnifit, Teflon, $0.8 \mathrm{~mm}$ i.d.), Gilson end-fittings and connectors. The support devices for tubular and reference electrodes, and the confluence point accessory were constructed in Perspex [28]. After reaching a stable baseline, the emf was recorded continuously by means of a home-made high-impedance data acquisition eight-channel box connected to a PC through the interface ADC 16 (Pico Tech., UK) and PicoLog for windows (version 5.07) software.

When necessary, the $\mathrm{pH}$ was measured by a Crison $\mathrm{CWL} / \mathrm{S} 7$ combined glass electrode connected to a decimilivoltammeter Crison, pH meter, GLP 22.

All chemicals were of analytical grade and de-ionized water (conductivity $<0.1 \mu \mathrm{Scm}^{-1}$ ) was employed. NOR, potassium tetrakis(4-chlorophenyl)borate (TpClTPB), $o$ NPOE, poly (vinyl chloride) (PVC) of high molecular weight, EGDMA, VP, and MAA were purchased from Fluka (www.sigmaaldrich.com). Benzoyl peroxide (BPO), methanol $(\mathrm{MeOH})$ and tetrahydrofuran (THF) were from Riedel-deHäen (www.sigmaaldrich.com).

\section{Solutions}

Stock solutions of NOR $0.01 \mathrm{M}$ were prepared in water by addition of a few drops of concentrated $\mathrm{HCl}$. Less concentrated NOR standards were prepared by suitable dilution in ultra-pure water. Buffer solutions were $0.01 \mathrm{M}$ HEPES $(\mathrm{pH} \pm 5.5)$. 
The effect of $\mathrm{pH}$ was studied by imputing $\mathrm{pH}$ variations on $200 \mathrm{~mL}$ of a NOR solution $1.0 \times 10^{-4} \mathrm{M}$. The $\mathrm{pH}$ of this solution was altered by little additions of either concentrated hydrochloric acid or saturated sodium hydroxide solution, freshly prepared.

The interference of other chemicals was evaluated for $1.0 \times 10^{-3} \mathrm{M}$ of interfering solution prepared in buffer and subsequent calibration with NOR standard.

Synthesis of host-tailored polymers

MIPs were prepared by placing the template (NOR, $1.0 \mathrm{mmol})$ in a glass tube $(14.0 \mathrm{~mm}$ i.d) with the functional monomer (5.0 mmol MAA/VP), the cross-linker (EGDMA, $20.0 \mathrm{mmol}$ ) and the radical initiator (BPO, $0.32 \mathrm{mmol}$ ), all dissolved in $3.5 \mathrm{~mL} \mathrm{MeOH}$. The mixture was sonicated, degassed with nitrogen for $5 \mathrm{~min}$, and cured at $70{ }^{\circ} \mathrm{C}$ for 30 min. Non-imprinted polymers (NIP) were also prepared in a similar way, by excluding the template from the procedure.

The resulting polymers were grounded and sieved to particle sizes ranging 50 to $150 \mu \mathrm{m}$. Extraction of the template molecule and washout of non-reacted species was carried out with methanol/acetic acid $(5: 1, \mathrm{v} / \mathrm{v})$. The absence of NOR in the MIP particles was confirmed by measuring the $277 \mathrm{~nm}$ absorbance of the washout solution; the particles were repeatedly washed until NOR was no longer detected. All polymers (MIP/MAA, NIP/MAA, MIP/VP, NIP/VP) were dried after, at $60{ }^{\circ} \mathrm{C}$ until constant weight.

\section{Preparation of norfloxacin sensors}

The sensing membranes were prepared by mixing $200 \mathrm{mg}$ of PVC, $400 \mathrm{mg}$ of plasticizer $o$ NPOE and $7 \mathrm{mg}$ of the sensing polymer (Table 1). Some membranes were also added of
$2 \mathrm{mg}$ of TpClPB, acting as anionic additive. The mixture was stirred until the PVC was well moistened, and dispersed in $3.0 \mathrm{~mL}$ THF. These membranes were placed in conductive supports of conventional or tubular shapes. Membranes were let dry for $24 \mathrm{~h}$ and conditioned in a $1 \times 10^{-3} \mathrm{molL}^{-1} \mathrm{NOR}$ solution. The electrodes were kept in this solution when not in use.

Potentiometric procedures

All potentiometric measurements were carried out at room temperature. Emf values of each electrode were measured in solutions of fixed $\mathrm{pH}$ and ionic strength. Increasing concentration levels of NOR were obtained by transferring $0.0200-10.0 \mathrm{~mL}$ aliquots of $1.0 \times$ $10^{-3} \mathrm{molL}^{-1}$ NOR aqueous solutions to a $100 \mathrm{~mL}$ beaker containing $50.0 \mathrm{~mL}$ of $5.0 \times 10^{-2} \mathrm{molL}^{-1}$ of HEPES buffer. Potential readings were recorded after stabilization to $\pm 0.2 \mathrm{mV}$ and emf was plotted as a function of logarithm NOR concentration. Calibration graphs were used for subsequent determination of unknown NOR concentrations.

\section{Binding experiments}

Binding experiments were carried out by placing $20.0 \mathrm{mg}$ of MIP particles in contact with $10.0 \mathrm{~mL}$ NOR solutions ranging $0.04-2 \mathrm{mM}$. The mixtures were oscillated for $12 \mathrm{~h}$ at room temperature and the solid phase separated by centrifugation $(3,000 \mathrm{rpm}, 10 \mathrm{~min})$. The concentration of free NOR in the supernatant was detected by UV spectrophotometry at $277 \mathrm{~nm}$. The amount of NOR bound to the polymer was calculated by subtracting the concentration of free NOR from the initial NOR concentration. The data obtained was used for Scatchard analysis.

Table 1 Membrane composition of PVC NOR sensors and their mean potentiometric features $(n=3)$ in $1.0 \times 10^{-2} \mathrm{molL}^{-1} \mathrm{HEPES}_{\mathrm{fufer}} \mathrm{pH} 5.5$

\begin{tabular}{|c|c|c|c|c|c|c|c|c|}
\hline Characteristic & ISE I & ISE II & ISE III & ISE IV & ISE V & ISE VI & ISE VII & ISE VIII \\
\hline \multicolumn{9}{|l|}{ Membrane materials } \\
\hline Sensing polymer & MIP/MAA & MIP/MAA & NIP/MAA & MIP/VP & MIP/VP & NIP/VP & - & - \\
\hline Additive & TpClPB & - & - & TpClPB & - & - & TpClPB & - \\
\hline Slope $\mathrm{mV}$ decade ${ }^{-1}$ & $67.1 \pm 2.8$ & $47.2 \pm 0.0$ & $43.7 \pm 0.88$ & $56.0 \pm 1.2$ & $52.5 \pm 0.14$ & $41.9 \pm 0.0$ & - & $20 \pm 6.0$ \\
\hline $\begin{array}{l}\text { Correlation } \\
\text { coefficient, } r^{2}(n=5)\end{array}$ & 0.991 & 0.996 & 0.991 & 0.996 & 0.999 & 0.995 & - & 0.985 \\
\hline Detection limit, $\mathrm{molL}^{-1}$ & 1.20 & 1.27 & 19.7 & 0.40 & 1.27 & 15.9 & - & 3.31 \\
\hline $\begin{array}{l}\text { Lower Limit of Linear } \\
\text { range, } \mathrm{molL}^{-1}\end{array}$ & $6.97 \times 10^{-6}$ & $4.00 \times 10^{-6}$ & $1.58 \times 10^{-4}$ & $5.97 \times 10^{-5}$ & $4.00 \times 10^{-6}$ & $2.74 \times 10^{-4}$ & - & $9.95 \times 10^{-5}$ \\
\hline Response time, $\mathrm{s}$ & $<15$ & $<15$ & $<15$ & $<15$ & $<15$ & $<15$ & $<15$ & $<30$ \\
\hline Standard deviation, $\sigma_{\mathrm{v}}(\mathrm{mV})$ & 2.9 & 0.0 & 1.3 & 0.0 & 1.1 & 1.3 & 0.07 & 3.61 \\
\hline Repeatability, $\mathrm{Cv}_{\mathrm{w}}(\%)$ & 2.7 & 0.0 & 5.3 & 0.0 & 2.1 & 1.27 & 0.4 & 10.54 \\
\hline
\end{tabular}


Table 2 Batch potentiometric determination of NOR ions in fish, urine and serum samples using VP/MIP based membrane sensor

\begin{tabular}{lcrl}
\hline Sample & $\begin{array}{l}\text { Standard Addition } \\
\left(\mu \mathrm{gml}^{-1}\right)\end{array}$ & \multicolumn{1}{l}{$\begin{array}{l}\text { Recovery } \\
(\%)\end{array}$} & \multicolumn{1}{l}{$\begin{array}{l}\text { Relative Error } \\
(\%)\end{array}$} \\
\hline Fish & 40.0 & $94.0 \pm 2.00$ & 6.0 \\
$\left(17 \mu \mathrm{gmL}^{-1}\right)$ & 50.0 & $105.0 \pm 0.10$ & $5.0 \pm 0.10$ \\
Urine & 20.0 & $105.2 \pm 0.10$ & $5.2 \pm 0.03$ \\
$\quad\left(17 \mu \mathrm{gmL}^{-1}\right)$ & 30.0 & $96.0 \pm 0.98$ & $4.0 \pm 0.01$ \\
$\quad$ Serum & 25.0 & $99.0 \pm 3.60$ & $2.6 \pm 0.92$ \\
$\quad\left(20 \mu \mathrm{gmL}^{-1}\right)$ & 50.0 & $107.3 \pm 3.60$ & $7.3 \pm 0.79$ \\
\hline
\end{tabular}

Determination of norfloxacin in fish

Constant weights of well grinded fish $(\sim 2.0 \mathrm{mg})$ from aquaculture origin were transferred to $15 \mathrm{~mL}$ tubes. A $10 \mathrm{~mL}$ portion of $0.01 \mathrm{molL}^{-1}$ HEPES buffer $\mathrm{pH} 5.5$ was added and thoroughly mixed with the fish sample. A sonication period of $5 \mathrm{~min}$ was allowed to ensure convenient extraction of the analyte. A supernatant liquid was obtained by centrifugation at $1000 \mathrm{rpm}$ and transferred into a $25 \mathrm{~mL}$ volumetric flask after filtration. Analytical measurements were conducted over the supernatant liquid after completing the flask to final volume with buffer.

Emf measurements in steady state were made by immersing the electrochemical cell in the sample test solution and waiting until equilibrium was reached (10$20 \mathrm{~s})$. The concentration of NOR was calculated using previous calibration data (Table 2).

\section{Determination of norfloxacin in biological samples}

For the analysis of biological fluids, $250 \mu \mathrm{l}$ of urine and serum were placed in a $25 \mathrm{~mL}$ volumetric flask and diluted to final volume with $1.0 \times 10^{-2} \mathrm{molL}^{-1}$ HEPES buffer $(\mathrm{pH}$ 5.5). The direct potential method was applied to determine NOR in urine and serum samples.

\section{Determination of norfloxacin in drug}

Potentiometric analysis was conducted on oral dosage forms of pharmaceutical preparations, commercially available as Norfloxacin, with a labeled amount of $400 \mathrm{mg}$ NOR/tablet. Two tablets were grounded and a representative suitable amount of powder was transferred to a $50-\mathrm{mL}$ calibrated flask. This powder was dissolved in water after sonication for $10 \mathrm{~min}$. A $1.0 \mathrm{~mL}$ aliquot of the clear supernatant was diluted with $1.0 \times 10^{-2} \mathrm{molL}^{-1}$ HEPES solution of $\mathrm{pH} 5.5$ in $100-\mathrm{mL}$ measuring flask. A $10-\mathrm{mL}$ aliquot of the previous solution was placed in the potentiometric cell for analytical measurement.

\section{Results and discussions}

NOR selective sensors are designed by template imprinting on VP and MAA monomers and non covalent binding between model molecule and MIP functionalities. Electrostatic interactions established are mostly of hydrogen bond nature [29]. NOR has both amino and carboxylic acid groups in its structure (Fig. 1) that may interact with either basic (VP) or acidic (MAA) monomers. "A" in Fig. 1 are the functional groups of the monomers: carboxylic acid or heteroaromatic amine from methacrylic acid or vinyl pyridine, respectively. The polymers were obtained by non-covalent imprint, thereby leading to electrostatic interactions with the template by means of the opposite polarities within the involved structures. Furthermore, they may establish hydrogen bonds between (i) the electrophillic hydrogen atoms that are attached to highly electronegative species and (ii) the nucleophilic atoms (oxygen and nitrogen).

General analytical performance of the sensors

NOR sensors contained MIP or NIP particles as electroactive materials dispersed in $o$ NPOE plasticizing solvent and PVC. Their main analytical features are shown in Table 1, and were evaluated by IUPAC recommendations (51). The sensors prepared with MAA and VP displayed a linear behavior after $4.0 \times 10^{-6} \mathrm{molL}^{-1} \mathrm{NOR}$, cationic slopes of 47.2 and $52.5 \mathrm{mV}$ decade $^{-1}$ and detection limits of $1.27 \mu \mathrm{gmL}^{-1}$, respectively. The corresponding NIP particles displayed low sensitivities, with cationic slopes of 43.7 and $41.9 \mathrm{mV}$ decade $^{-1}$. Their linear responses started at $1.58 \times 10^{-4}$ and $2.74 \times 10^{-4} \mathrm{molL}^{-1} \mathrm{NOR}$ and the detection limits were 19.7 and $15.9 \mu \mathrm{gmL}^{-1}$, respectively. In general terms, MIP sensors made with VP and MAA monomers displayed near-Nerstian behavior while those with NIP particles showed the widest linear response ranges (Fig. 2). Blank membranes with only PVC and oNPOE (ISE VIII) were also prepared and showed no response towards NOR, confirming that the previous behavior resulted solely from the MIP or NIP particles (see Fig. 2).

To improve the operating features of the previous membranes, MIP-based sensors were added of TpCITPB (Table 1), an anionic lipophilic compound. Typically, the addition of an ionic compound of lipophilic nature to potentiometric sensors reduces the anionic interference and lowers the electrical resistance of the membranes [30]. In terms of analytical performance, this procedure was expected to widen the linear range with theoretical slope. Sensors based in MIP/MAA and MIP/VP with additive, showed linear response started $6.97 \times 10^{-6}$ and $5.97 \times 10^{-5} \mathrm{molL}^{-1}$, 1.20 and $0.40 \mu \mathrm{gmL}^{-1}$ detection limits, and near-Nernstian 
Fig. 1 Chemical structure of monomers, cross-linker and molecularly-imprinted polymers showing non-covalent binding sites to NOR

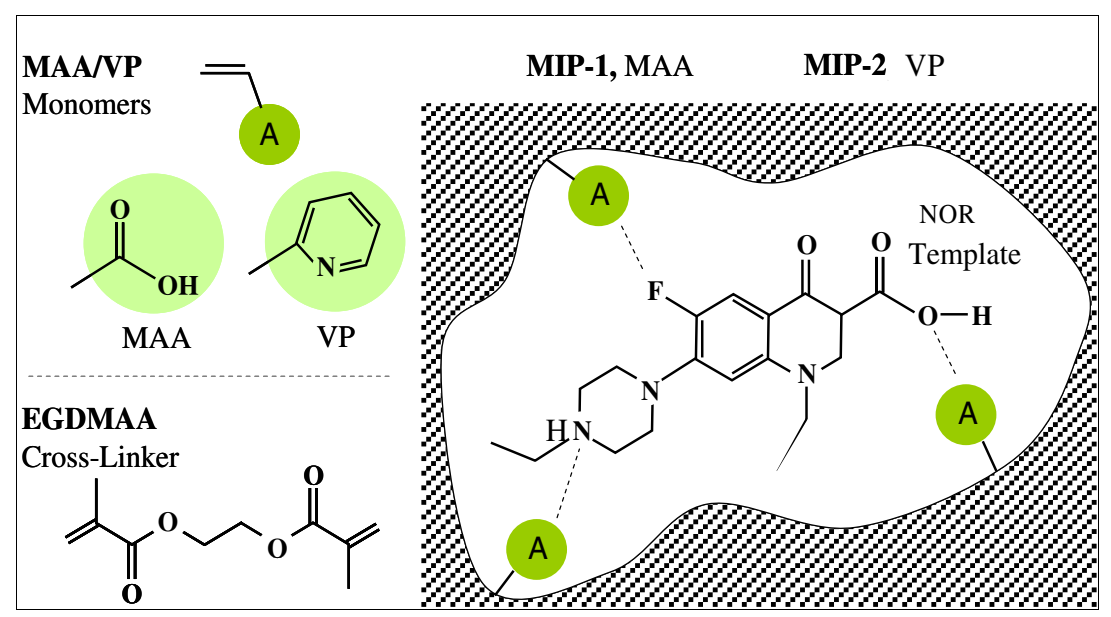

responses of 67.1 and $56.0 \mathrm{mV} \mathrm{decade}{ }^{-1}$, respectively. When compared to the corresponding sensors without additive, a significant improve in terms of slope was observed for MAA and VP sensors (see Fig. 2). This improvement could not be attributed to the additive alone because membranes with additive and without ionophore (ISE VII) were not able to present a Nernstian response (see Fig. 2).

\section{Effect of $\mathrm{pH}$}

The influence of $\mathrm{pH}$ on the potentiometric response of the sensors was examined over a $\mathrm{pH}$ range of $1.5-11$. The $\mathrm{pH}$ of the NOR solution was adjusted with either hydrochloric acid and/or sodium hydroxide solutions (Fig. 3).

For MIP/MAA and VP the $\mathrm{pH}$ plot shows that $\mathrm{pH}$ changes over the range 2-6 and 8-11 had no significant effect on the potentiometric response. The corresponding sensors with additive showed a decrease in the potential values as the $\mathrm{pH}$ increased; the electrodes acted as an anion-exchanger under these conditions NIP/MAA and VP were less affected by $\mathrm{pH}$, showing operational $\mathrm{pH}$ ranges lying within 3-11.

\section{Selectivity of the sensors}

Selectivity of the chemical sensor is one of the most important potentiometric features regarding its analytical application. One component of the selective membrane that exerts great influence upon this property is the electroactive material, as the mechanism of selectivity is mainly governed by stereospecific and electrostatic aspects. The selectivity profile of each sensor was evaluated by means of potentiometric selectivity coefficients $\left(K_{N O R, J}^{P O T}\right)$, assessed by mixed solution method (MSM) [31].

The $\left(K_{A, B}^{P O T}\right)$ indicated the degree of preferential interaction for NOR over potentially interfering species that are common in biological and food samples, such as other fluoroquinolones used in aquaculture, namely, enrofloxacin (ENR) or other antibiotics namely tetracycline (Tc), sulfadiazine (SDZ), and dopamide (DPM). Glucose (Gly), hydroxylamine (HDXL), ammonium chloride $\left(\mathrm{NH}_{4} \mathrm{Cl}\right)$, lithium carbonate $\left(\mathrm{CO}_{3} \mathrm{Li}\right)$ and creatinine $\left(\mathrm{Crea}^{+}\right)$were also included as possible interfering species.

The selectivity coefficients for MSM were plotted in Fig. 4 (expressed in $\log K_{N^{P O R^{+}, J^{+}}}$) and calculated after the following equation

$K_{N O R, J}^{P O T}=a_{N O R} /\left(a_{J}\right)^{Z_{N O R} / Z_{J}}$

where $a_{J}$ is $1.0 \times 10^{-3} \mathrm{molL}^{-1}$ of interfering species, $Z$ the ionic charges of main and interfering ions and $a_{N O R}$ the

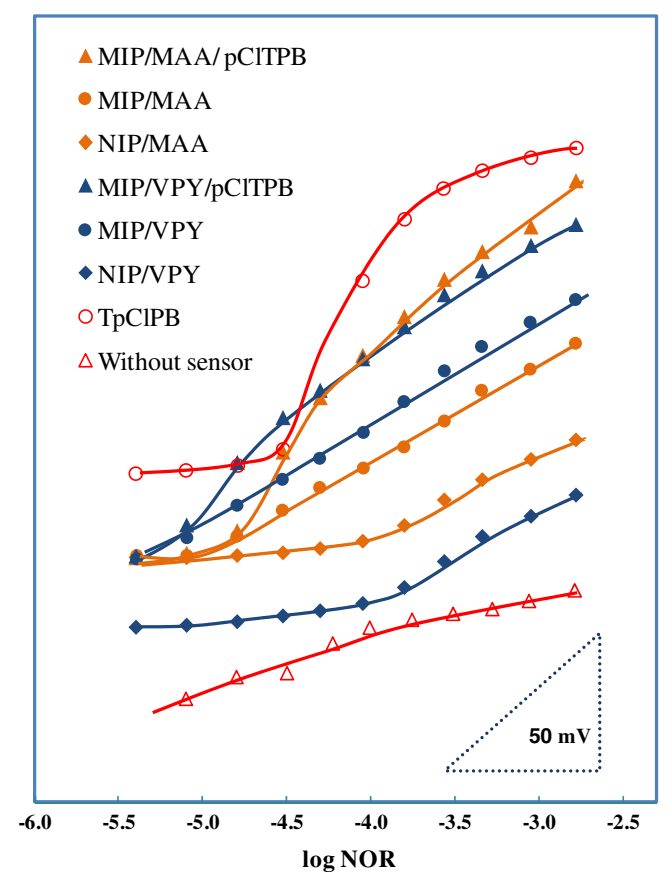

Fig. 2 Potentiometric response of NOR PVC membrane sensors under static mode of operation 


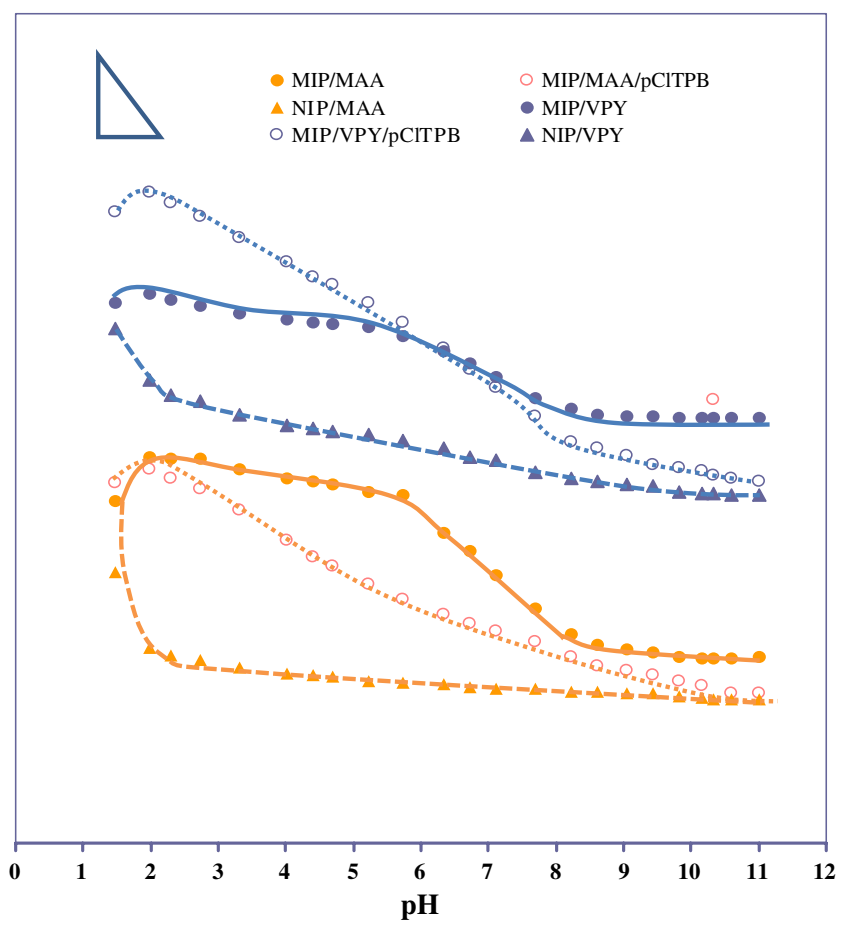

Fig. 3 Reilley diagram

intersection of the extrapolated linear portions of the plot emf vs. the logarithm of NOR concentration.

ISEs with MIP/MAA-based sensing materials (ISE I) showed the best selectivity, with a relative order of $\log \mathrm{K}^{\text {pot }}$ $\mathrm{NOR}>>\mathrm{ENR}>\mathrm{CO}_{3} \mathrm{Li}>\mathrm{NH}_{4} \mathrm{Cl}>\mathrm{Tc}^{+}>\mathrm{DPM}>\mathrm{HXL}>$ SDZ $>$ GLT $>$ Glu $>\mathrm{Crea}^{+}$. The corresponding sensors with additive (ISE II) displayed higher $\log \mathrm{K}^{\text {pot }}$ values (being less selective), indicating that the ionic additive improved the preference of the sensor for NOR. The relative order of log $\mathrm{K}^{\text {pot }}$ was NOR $>>\mathrm{ENR}>\mathrm{CO}_{3} \mathrm{Li}>\mathrm{NH}_{4} \mathrm{Cl}>\mathrm{HXL}>\mathrm{GLT}>$ Glu $>\mathrm{TC}^{+}>\mathrm{SDZ}>\mathrm{DPM}>\mathrm{Crea}^{+}$. NIP/MAA (ISE III) showed the relative order pattern of $\log \mathrm{K}^{\text {pot }} \mathrm{NOR}>>$ $\mathrm{CO}_{3} \mathrm{Li}>\mathrm{NH}_{4} \mathrm{Cl}>\mathrm{Crea}^{+}>\mathrm{ENR}>\mathrm{GLT}>\mathrm{SDZ}>\mathrm{TC}^{+}>$ DPM $>$ Glu $>$ HXL, being the MAA sensors of lower selectivity.

ISEs based on VP sensing materials displayed different behaviors. MIP (ISE IV) and NIP (ISE VI) based sensors showed the $\log \mathrm{K}^{\text {pot }}$ sequences NOR $>>\mathrm{CO}_{3} \mathrm{Cl}>\mathrm{ENR}>$ $\mathrm{NH}_{4} \mathrm{Cl}>\mathrm{Tc}^{+}>\mathrm{DPM}>\mathrm{HXL}>\mathrm{SDZ}>\mathrm{Crea}^{+}>\mathrm{GLT}$ and $\mathrm{NOR}>>\mathrm{CO}_{3} \mathrm{Cl}>\mathrm{NH}_{4} \mathrm{Cl}>\mathrm{Tc}^{+}>\mathrm{Crea}^{+}>\mathrm{DPM}>\mathrm{SDZ}>$ ENR $>$ GLT $>$ Glu $>$ HXL, respectively. MIP/VP with additive followed the sequence NOR $>>\mathrm{ENR}>\mathrm{CO}_{3} \mathrm{Li}>$ $\mathrm{NH}_{4} \mathrm{Cl}>\mathrm{DPM}>\mathrm{Tc}^{+}>\mathrm{HXL}>\mathrm{Crea}^{+}>\mathrm{GLT}>\mathrm{Glu}>\mathrm{SDZ}$. In this case the additive provided lower $\log \mathrm{K}^{\text {Pot }}$, improving the selectivity of the MIP/VP based sensor.

Overall, the observed behavior is clearly anti-Hofmeister and it seems clear that piperazinyl ring and the cyclopropyl group in NOR play an important role in the recognition mechanism of the imprinted polymers. This was more evident when MAA and VP NIP particles displayed the worst selectivity pattern. Compounds of positively charged nitrogen atoms had high similarity to the chemical structure of the main ion but their logarithm selectivity coefficients were always below -1 . This suggested small interference from other quaternary ammonium salts or compounds of positively charged nitrogen atoms, being the binding to

Fig. 4 Potentiometric selectivity coefficients $\left(\log K^{P O T}\right)$ of NOR membrane based sensors, in $0.01 \mathrm{molL}^{-1}$ HEPES buffer of $\mathrm{pH} 5.5$

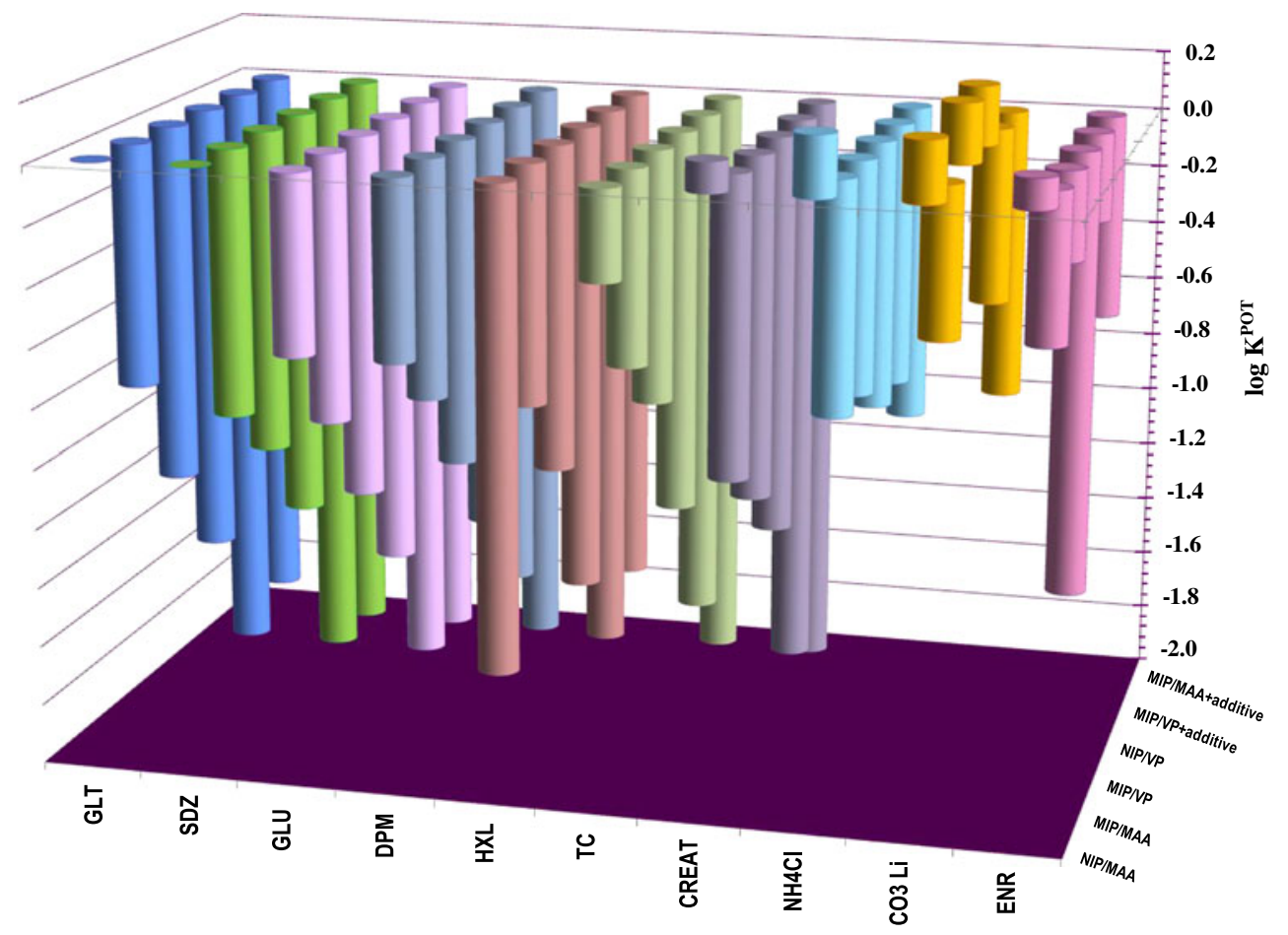


NOR the preferable process. Other pharmaceuticals of organic nature also exerted small interference.

\section{Binding properties of molecular imprinting polymers}

The modes of binding and site distributions in the interaction of NOR with the adsorbent surfaces of MIP polymers was initially evaluated by performing binding experiments, in which fixed amounts of imprinted polymers were incubated with different concentrations of NOR until equilibrium was reached $(55,56)$. The resulting binding capacity of MIPs was calculated according to following equation:

$Q=\frac{\mu \operatorname{mol}(\text { NOR bound })}{g(M I P)}=\frac{\left(C_{i}-C_{f}\right) V_{s} \times 1000}{M_{M I P}}$

where $\mathrm{Q}$ is binding capacity of MIPs $(\mu \mathrm{mol} / \mathrm{g}), \mathrm{C}_{\mathrm{i}}$ the initial NOR concentration $(\mu \mathrm{mol} / \mathrm{mL}), \mathrm{C}_{\mathrm{f}}$ the final NOR concentration $(\mu \mathrm{mol} / \mathrm{mL}), V_{\mathrm{s}}$ the volume of solution tested $(\mathrm{mL})$, $\mathrm{M}_{\text {MIP }}$ the mass of dried polymer (mg). Binding capacities were used to plot the adsorption isotherms (Fig. S1A1 and A2, in supplementary material). The adsorption data showed that the binding capacity of imprinted polymer increased with the increasing of the initial concentration of NOR, reaching to saturation at higher concentrations. MIPVP particles displayed a higher affinity for template molecule than MIP-MAA.

The binding data were further processed with Scatchard analysis, providing important information on binding properties of the imprinted particles (54). The Scatchard equation,

$\mathrm{Q} / \mathrm{C}_{\text {free }}=\left(\mathrm{Q}_{\max }-\mathrm{Q}\right) / \mathrm{K}_{d}$

was applied for this purpose, where $\mathrm{Q}$ is the binding capacity; $\mathrm{C}_{\text {free }}$ the free analytical concentration at equilibrium $(\mu \mathrm{mol} / \mathrm{L}) ; \mathrm{Q}_{\max }$ is the maximum apparent binding capacity; and $\mathrm{K}_{\mathrm{D}}$ is the dissociation constant at binding site. The equilibrium dissociation constant is calculated from the slopes and the apparent maximum number of binding sites from the $y$-intercepts in the linear plot of $\mathrm{Q} / \mathrm{C}_{\text {free }}$ versus $\mathrm{Q}$.

The Scatchard plot in Fig. S1B1 and B2 (in supplementary material) showed a linear behavior for MAA and VP imprinted polymers, suggesting the existence of a specific binding to imprinted cavities. $K_{d}$ and $Q_{\max }$ were $1310 \mu \mathrm{mol} / \mathrm{L}$ and $184 \mu \mathrm{mol} / \mathrm{g}$ for MIP/MAA, and $1181 \mu \mathrm{mol} / \mathrm{L}$ and $192 \mu \mathrm{mol} / \mathrm{g}$ for MIP/VP, respectively. Based on the existence of a single kind of binding site in the MIPs, it is possible to infer that binding between MIP and template is made by means of hydrogen bonds that involve either $\mathrm{O}$ (in MAA) or $\mathrm{N}$ (in VP) and the $\mathrm{O} / \mathrm{H}$ bonds in NOR molecules.
Optimization of flow injection system

For the routine control of an analyte, the continuous mode of operation is of regular selection. This may be achieved by means of flow injection analysis systems. These are particularly attractive in view of their versatility, simplicity and suitability for large-scale analyses. The flow assembly was double-channel, allowing the on-line adjustment of $\mathrm{pH}$ and ionic strength. A flow cell of tubular configuration was used to accommodate the potentiometric device. This cell was of simple fabrication, and allowed full membrane/ sample contact, maintaining the general features of conventional configuration ISEs in terms of homogeneity, thickness and fixed area. To take full advantages of this FIA system, flow-rate and injection volume were optimized in terms of sensitivity, sampling-rate, reagent consumption and wastewater generation.

The sample loop was varied within 160 and $500 \mu \mathrm{L}$ (Fig. S2A, in supplementary material). For each injection volume, a set of NOR standards ranging $7.85 \times 10^{-5}$ to $2.5 \times$ $10^{-3} \mathrm{molL}^{-1}$ was injected into the buffer carrier stream. For the sample loop effect, only the injection of $160 \mu \mathrm{L}$ resulted in slightly lower slope, $58 \mathrm{mV}$ decade $^{-1}$. For higher volumes the slope of the potentiometric response remained almost constant (less than $5 \%$ increase) $60-71 \mathrm{mV}$ decade $^{-1}$ for sample Loop 350 and $500 \mu \mathrm{L}$ respectively. This observation was coupled to decreased sampling-rates, dispersion, sample consumption and waste generation.

The effect of flow rate was examined from 4.7 to $9.4 \mathrm{~mL}$ $\min ^{-1}$ for NOR solution $3.3 \times 10^{-4} \mathrm{M}$ (Fig. S2B, in supplementary material). No significant changes in slope were observed, but the peak width and peak height decreased with increasing flow-rates. For flow rates $\leq 4.0 \mathrm{mLmin}^{-1}$ the tubular sensor required long time to recover to base line lowering the number of sample outputs.

Main analytical features recorded under optimum flow conditions are presented in Fig. 4 and S1. Variation or fluctuation of the base line did not exceed $\pm 5 \%$ of the peak height. The sensor of MIP/VP with additive was used in this study for showing the best compromise between selectivity and sensitivity. This sensor gave slopes of $68.2 \mathrm{mV}$ decade ${ }^{-1}$ with detection limits of $20.4 \mu \mathrm{gmL}^{-1}$. The sampling-rate was approximately 89 runs per hour.

Analytical application

\section{Determination of norfloxacin in fish}

The method was also used to determine NOR in fish samples [32] that are typically produced in aquaculture: salmon, trout and seabass. Fish meat was grinded and spiked to $1.57 \mu \mathrm{gmL}^{-1} \mathrm{NOR}$. A good agreement was found between added and found amounts of NOR. Results of the 
potentiometric analysis conducted in steady state showed recoveries ranging $94 \%-105 \%$ with an average relative standard deviation of $1.0 \%$. The $t$-student and $\mathrm{F}$ tests confirmed that there were no significant differences between the means and variances of static and hydrodynamic potentiometric sets of results.

\section{Determination of norfloxacin in tablets and biological samples}

Norfloxacine-Rathiopharm tablets with a labeled amount of $400 \mathrm{mg}$ NOR were analyzed by direct potentiometric analysis. Results of the potentiometric analysis conducted in steady state showed recoveries ranging $94.5 \%-105.7 \%$ with an average relative standard deviation of $1.5 \%$. Urine samples were analyzed [33] for theoretical concentrations of 20 and $30 \mu \mathrm{g} / \mathrm{mL}$. Mean values obtained were 21.0 and $31.2 \mu \mathrm{g} / \mathrm{mL}$, respectively. These results corresponded to recoveries ranging $105.7 \%$ to $96 \%$. Serum samples were analyzed for theoretical concentrations of 25 and $50 \mu \mathrm{g} / \mathrm{mL}$. Results of the potentiometric analysis conducted in steady state showed recoveries ranging $94 \%-107.3 \%$ with an average relative standard deviation of 3.6. The $t$-student and $\mathrm{F}$ tests confirmed that there were no significant differences between the means and variances of the labeled amount.

\section{Conclusions}

Molecular imprinting technique was employed to produce NOR host-tailored sensors for potentiometric transduction. MAA and/or VP were used as monomers to produce different MIP materials. ISEs with these ionophores presented infraNernstian slopes and required an additive for improving the overall analytical features. Both MAA and VP based sensors with additive offered good potentiometric analytical features capable of discriminating other fluoroquinolones in aqueous media. Blank membranes were prepared without ionophore showing that this component was fundamental to produce suitable analytical response. Advantages of these sensors include the simplicity in designing, short measurement time, good precision, high accuracy, high analytical throughput, low limit of detection and good selectivity.

The MIP/VP sensors were successfully applied to the analysis of pharmaceutical products, food and biological samples. This method is simple, of low cost, precise, accurate and inexpensive regarding reagent consumption and equipment involved. Wastewaters discharged are of small concern to environment regarding its volume and composition. The tubular devices produce quicker responses for NOR than those provided by microbiological methods and are suitable for screening purposes.
Acknowledgements The authors acknowledge the financial support from FCT, Fundação para a Ciência e Tecnologia, and FEDER by means of project PTDC/AGR-AAM/68359/2006.

\section{References}

1. Cabello FC (2006) Heavy use of prophylactic antibiotics in aquaculture: a growing problem for human and animal health and for the environment. Environ Microbiol 8:1137-1144

2. Maki T, Hirono I, Kondo H, Aoki T (2008) Drug resistance mechanism of the fish-pathogenic bacterium Lactococcus garvieae. J Fish Dis 31:461-468

3. Council Regulation (EEC) $2377 / 90$ of 26 June 1990. Consolidated with previous amendments and published by 19 November 2005 .

4. Appelbaum PC, Hunter PA (2000) The fluoroquinolone antibacterials: past, present and future perspectives. Int $\mathrm{J}$ Antimicrob Agents 16:5-15

5. Pimentel FL, Dolgner A, Guimaraes J, Quintas M, Mario-Reis J (1998) Efficacy and safety of norfloxacin $800 \mathrm{mg}$ once-daily versus norfloxacin $400 \mathrm{mg}$ twice-daily in the treatment of uncomplicated urinary tract infections in women: a double-blind, randomized clinical trial. J Chemother 10:122-127

6. Gräslund S, Bengtsson BE (2001) Chemicals and biological products used in south-east Asian shrimp farming, and their potential impact on the environment - a review. Sci Total Environ 280:93-131

7. Stoilova N (2008) Determination of quinolones in fish tissues with high performance liquid chromatography with fluorescence detection. J Univer Chem Techn Metallurgy 43:423-426

8. Valdés MG, Valdez González AC, García Calzón JA, Díaz-García ME (2009) Analytical nanotechnology for food analysis. Microchim Acta 166:1-19

9. Cabello FC (2004) Antibiotics and aquaculture in Chile: implications for human and animal health. Rev Med Chile 132:10011006

10. Park SK, Kim M, Sho YS, Chung SY, Hu S, Lee JO, Hong MK, Kim MC, Kang JS, Jhee OH (2007) Microbiological and chemical detection of antibiotic residues in livestock and seafood products in the Korean market. Food Sci Biotechnol 16:868-872

11. Kassab NM, Singh AK, Kedor-Hackmam ERM, Santoro MIRM (2005) Quantitative determination of ciprofloxacin and norfloxacin in pharmaceutical preparations by high performance liquid chromatography. Brazilian J Pharm Sci 41:507-513

12. Dufresne G, Fouquet A, Forsyth D, Tittlemier SA (2007) Multiresidue determination of quinolone and fluoroquinolone antibiotics in fish and shrimp by liquid chromatography/tandem mass spectrometry. J AOAC Int 90:604-312

13. Zhang YZ, Zhang Z, Zhou YC, Liu L, Zhu Y (2007) Determination of fluorinated quinolone antibacterials by ion chromatography with fluorescence detection. J Zhejiang Univ Sci B 8:302-306

14. Chui-Shiang C, Wei-hsien W, Chin-En T (2008) Simultaneous determination of eleven quinolones antibacterial residues in marine products and animal tissues by liquid chromatography with fluorescence detection. J Food Drug Anal 16:87-96

15. Schneider MJ, Vazquez-Moreno L, Bermudez-Almada MD, Guardado RB, Ortega-Nieblas M (2005) Multiresidue determination of fluoroquinolones in shrimp by liquid chromatographyfluorescence-mass spectrometry. J AOAC Int 88:1160-1166

16. McCourt J, Bordin G, Rodriguez AR (2003) Development of a capillary zone electrophoresis-electrospray ionisation tandem mass spectrometry method for the analysis of fluoroquinolone antibiotics. J Chromatogr A 990:259-269 
17. Tittlemier SA, Gélinas JM, Dufresne G, Haria M, Querry J, Cleroux C, Ménard C, Delahaut P, Singh G, Durand NF, Godefroy SB (2008) Development of a direct competitive enzyme-linked immunosorbent assay for the detection of fluoroquinolone residues in shrimp. Food Anal Methods 1:28-35

18. Cosofret VV, Buck RP (1996) Recent advances in pharmaceutical analysis with potentiometric membrane sensors. Crit Rev Anal Chem 24:1-58

19. Wulff G (2002) Enzyme-like catalysis by molecularly imprinted polymers. Chem Rev 102:1-27

20. Peter S, Schweitz L, Nilsson S (2003) Molecularly imprinted polymers in capillary electrochromatography: recent developments and future trends. Electrophoresis 24:3892-3899

21. Lavignac N, Allender CJ, Brain KR (2004) Current status of molecularly imprinted polymers as alternatives to antibodies in sorbent assays. Anal Chim Acta 510:39-145

22. Kriz O, Ramstrom O, Mosbach K (1997) Molecular imprintingNew possibilities for sensor technology. Anal Chem 69:345A-349A

23. Andersson LI (2000) Molecular imprinting for drug bioanalysisA review on the application of imprinted polymers to solid-phase extraction and binding assay. J Chromatogr B 739:163-173

24. Kamel AH, Teixeira F, Almeida SAA, Sales MGF (2008) Novel potentiometric sensors of molecular imprinted polymers for specific binding of chlormequat. Electroanalysis 20:194-202

25. Lopez MCB, Castanon MJL, Ordieres AJM, Blanco PT (2004) Electrochemical sensors based on molecularly imprinted polymers. Trends Anal Chem 23:36-48
26. Faridbod F, Ganjali MR, Dinarvand R, Norouzi P (2008) Developments in the field of conducting and non-conducting polymer based potentiometric membrane sensors for ions over the past decade. Sensors 8:2331-2412

27. Hutchins RS, Bachas LG (1995) Nitrate-selective electrode developed by electrochemically mediated imprinting doping of polypyrrole. Anal Chem 67:1654-1660

28. Kamel AH, Almeida SAA, Sales MGF, Moreira FTC (2009) Sulfadiazine-potentiometric sensors for flow and batch determinations of sulfadiazine in drugs and biological fluids. Anal Sci $25: 365-371$

29. Dickert FL, Hayden O (1999) Molecular imprinting in chemical sensing. Trends Anal Chem 18:192-199

30. Telting-Diaz M, Bakker E (2001) Effect of lipophilic ionexchanger leaching on the detection limit of carrier-based ionselective electrodes. Anal Chem 73:5582-5589

31. IUPAC Analytical Chemistry Division Commission on Analytical Nomenclature (2000) Pure Appl Chem 72:1851

32. Wang J, Pan M, Fang G, Wang S (2009) Preparation of a novel molecularly imprinted polymer by a sol-gel process for on-line solid-phase extraction coupled with high performance liquid chromatography to detect trace enrofloxacin in fish and chicken samples. Microchim Acta 166:295-302

33. Yunhua H, Jiuru L, Hongge Z, Jianxiu D (2005) Molecular imprinting-chemiluminescence determination of norfloxacin using a norfloxacin-imprinted polymer as the recognition material. Microchim Acta 149:239-244 